\title{
Novel diagnostic and therapeutic techniques for surveillance of dysplasia in patients with inflammatory bowel disease
}

\author{
M lacucci MD PhD ${ }^{1}, \mathrm{~T}$ Uraoka MD PhD², M Fort Gasia MD ${ }^{1}, \mathrm{~N}$ Yahagi MD PhD 2
}

M Iacucci, T Uraoka, M Fort Gasia, N Yahagi. Novel diagnostic and therapeutic techniques for surveillance of dysplasia in patients with inflammatory bowel disease. Can J Gastroenterol Hepatol 2014;28(7):361-370.

The risk for developing dysplasia and colorectal cancer in patients with longstanding inflammatory bowel disease (IBD) involving the colon is well documented. Random biopsies during white-light, standard-definition colonoscopy (33 to 50 biopsies) with or without dye spraying chromoendoscopy has been the recommended strategy in North America to detect dysplastic lesions in IBD. However, there are several limitations to this approach including poor physician adherence, poor sensitivity, increased procedure time and considerable cost. The new generation of high-definition endoscopes with electronic filter technology provide an opportunity to visualize colonic mucosal and vascular patterns in minute detail, and to identify subtle flat, multifocal, polypoid and pseudopolypoid neoplastic and non-neoplastic lesions. The application of these new technologies in IBD is slowly being adopted in clinical practice. In addition, the advent of confocal laser endomicroscopy provides an opportunity to explore real-time histology, thus redefining the understanding and characterization of the lesions in IBD. There is emerging evidence that serrated adenomas are also associated with longstanding IBD colitis and may be recognized as another important contributing factor to colorectal cancer development. The circumscribed neoplastic lesions can be treated using endoscopic therapeutic management such as mucosal resection or, especially, endoscopic submucosal dissection. This may replace panproctocolectomy in selected patients. The authors review the potential of these techniques to transform endoscopic diagnosis and therapeutic management of dysplasia in IBD.

Key Words: Chromoendoscopy; Confocal laser endomicroscopy; Endoscopic submucosal dissection; High-definition endoscopic technique iScan; Inflammatory bowel disease; Narrow band imaging

\begin{abstract}
Des techniques diagnostiques et thérapeutiques novatrices pour surveiller la dysplasie chez les patients atteints d'une maladie inflammatoire de l'intestin
\end{abstract}

Le risque de dysplasie et de cancer colorectal chez les patients atteints d'une maladie inflammatoire de l'intestin (MII) de longue date qui touche le côlon est bien étayé. En Amérique du Nord, la stratégie recommandée consiste à effectuer des biopsies aléatoires pendant une coloscopie en lumière blanche à définition standard (33 à 50 biopsies) avec ou sans chromo-endoscopie afin de déceler les lésions dysplasiques en cas de MII. Cependant, cette méthode comporte plusieurs limites, y compris la mauvaise adhérence par le médecin, la faible sensibilité, la durée plus longue de l'intervention et le coût élevé. La nouvelle génération d'endoscopies à haute définition faisant appel à la technologie de filtre électronique permet de visualiser les profils muqueux et vasculaires du côlon dans tous ses détails et de repérer les lésions néoplasiques ou non subtiles, plates, multifocales, polypoïdes et pseudopolypoïdes. Ces nouvelles technologies sont lentement adoptées en pratique clinique dans les cas de MII. De plus, l'endomicroscopie confocale permet d'explorer l'histologie en temps réel, ce qui apporte un nouvel éclairage sur la compréhension et la caractérisation des lésions causées par les MII. D’après des données émergentes, les adénomes dentelés s'associent à une colite de longue date et peuvent être considérés comme un autre facteur contributif important à l'apparition du cancer colorectal. On peut traiter les lésions néoplasiques circonscrites au moyen d'un traitement endoscopique comme une résection muqueuse, ou plus particulièrement, une dissection sous-muqueuse endoscopique. Chez certains patients, cette intervention pourrait remplacer la panproctocolectomie. Les auteurs examinent le potentiel de ces techniques à transformer le diagnostic endoscopique et la prise en charge thérapeutique de la dysplasie en cas de MII.

\begin{abstract}
Tnflammatory bowel disease (IBD) represents a special example of screening and surveillance for colorectal cancer (CRC) in a population at higher risk for developing neoplastic lesions. In this patient group, other potential techniques for screening, such as the fecal occult blood test, fecal immunochemical test or flexible sigmoidoscopy, are not valid. Special techniques at colonoscopy need to be used to diagnose early neoplastic changes. In the present review, we highlight the magnitude of the problem of neoplastic lesions associated with IBD and, subsequently, discuss novel and emerging diagnostic techniques and emerging therapeutic colon-sparing techniques.
\end{abstract}

\section{METHODS}

Appropriate articles were identified by electronic search of PubMed, MEDLINE and Embase between January 1980 and October 2013 using the key words: dysplasia, CRC and IBD, surveillance in IBD, novel endoscopic techniques in IBD, therapeutic endoscopy in IBD, endoscopic mucosal resection (EMR), endoscopic submucosal dissection (ESD), pseudopolyps, dysplasia-associated lesion or mass, adenoma associated lesion or mass, chromoendoscopy, autofluorescence, virtual chromoendoscopy and confocal endomicroscopy. Additionally, articles were identified by manually searching references cited in important articles and reviews.

\section{INCIDENCE AND PREVALENCE OF CRC IN PATIENTS WITH IBD}

Several epidemiological studies have demonstrated an increased risk for CRC in patients with IBD, estimated to be two to five times higher than in the general population of the same age group. The overall

\footnotetext{
${ }^{1}$ Division of Gastroenterology $\mathcal{E}$ Hepatology, IBD Unit, University of Calgary, Calgary, Alberta; ${ }^{2}$ Division of Research and Development of Minor Invasive Treatment, Cancer Center, School of Medicine, Keio University, Tokyo, Japan

Correspondence: Dr M Iacucci, Division of Gastroenterology, Department of Medicine, University of Calgary, 2500 University Drive Northwest, Calgary, Alberta T2N 1N4. Telephone 403-592-5015, fax 403-592-5090, e-mail miacucci@ucalgary.ca

Received and accepted for publication April 17, 2014
} 
prevalence of CRC in ulcerative colitis (UC) patients was originally analyzed in a large meta-analysis and estimated to be $3.7 \%$ (1). However, more recent studies suggest that the prevalence of CRC in IBD may be much lower (2). Although the cancer risk reported from different centres may be variable, there is a trend toward decreasing incidence over decades (3). A recent population-based study from Denmark (4) reported that the overall risk for CRC in patients with UC has decreased markedly over time and no longer exceeds that of the general population, at least in the first decade after UC diagnosis. A key factor that has contributed to this decrease is believed to be the widespread use of 5 -aminosalicylate because several (but not all) studies have suggested that 5-aminosalicylate may decrease cancer incidence (5).

Well-defined risk factors, such as early onset of IBD, family history of $\mathrm{CRC}$, long duration of colitis, ongoing endoscopic or histological inflammation, and more extensive or pancolonic disease, have been identified $(6,7)$. A concurrent diagnosis of primary sclerosing cholangitis (PSC) represents a high risk for colonic neoplasia - this represents a distinct subgroup of IBD with a distictive phenotype and genotype. A population-based study conducted in Canada between 2000 and 2004 identified all patients with a diagnosis of PSC using regional databases. Forty-five PSC patients with UC or Crohn disease (CD) were identified. Five (11.1\%) patients were diagnosed with neoplastic changes: low-grade dysplasia $(n=2)$, dysplasia-associated lesion or mass $(n=2)$ or CRC $(n=1)$ during the five-year follow-up period, yielding an incidence rate of 3.1 events per 100 person-years (95\% CI 1.0 to 7.2/100 person-years). Colonic neoplasia in PSC and IBD can be commonly detected within two to five years' duration of disease because PSC has an insidious onset with subtle inflammation over a long asymptomatic or low-grade symptom phase $(8,9)$.

Colonic CD is also associated with an increased risk for colon cancer $(10,11)$. In a recent meta-analysis of population-based studies, the risk for colon cancer in CD was increased (SIR 1.6 [95\% CI 1.2 to 2.0]) (12). American Gastroenterology Association guidelines recommend surveillance for colon cancer in patients with colonic CD starting from eight to 10 years of disease duration (13). The nature and intervals for surveillance are similar to extensive UC, although such a recommendation is largely empirical. The patchy nature of colonic involvement in $\mathrm{CD}$ and presence of strictures may pose challenges to surveillance.

\section{DYSPLASIA, ADENOMA-LIKE MASS, AND} DYSPLASIA-ASSOCIATED MASS OR LESION IN IBD

In sporadic CRC, the dysplastic precursor lesion is the adenomatous polyp, which is the well-recognized single discrete focus of neoplasia that is typically managed by endoscopic polypectomy. In contrast, in patients with longstanding IBD, dysplasia may be polypoid or flat, localized, diffuse or multifocal and, once found, may mark the entire colon as being at heightened risk for neoplasia, although this may not be inevitable $(14,15)$. These differences in morphology and biological behaviour between a 'colitis-associated dysplasia' and a sporadic adenoma have led to considerable ambiguity in the nomenclature for neoplastic lesions in IBD. In an effort to avoid this ambiguity, the term 'intraepithelial neoplasia' (IEN) has been suggested as an alternative to describe all neoplastic lesions arising in IBD patients; this is especially true in the Japanese literature.

One of the unique features of dysplasia in IBD is its macroscopic heterogeneity in characteristics. Dysplasia is classified macroscopically as flat or elevated, depending on whether it corresponds to an endoscopically visible lesion $(16,17)$. Flat dysplasia is detected microscopically in random biopsy specimens from relatively unremarkable mucosa at endoscopy. Presently, its detection depends on adequate sampling of the mucosa by the endoscopist; however, the technology to detect these endoscopically is rapidly evolving. Elevated lesions, conventionally referred to as dysplasia-associated lesion or mass (DALM) include single and/or multiple polyps, bumps, plaques and velvety patches and these can easily remain hidden among the inflammatory abnormalities encountered in IBD (15). Recently, specific definitions of adenoma-like mass or dysplasia (ALM or ALD) have been proposed. The term 'ALM' is applied to polypoid dysplasia with no adjacent flat component, endoscopically indistinguishable from a sporadic (sessile or pedunculated) polyp. Histology is of little help in differentiation of DALM from ALM and this distinction basically relies on endoscopic appearance (18).

The histological classification of dysplasia is based on the 1983 consensus report by Riddell et al (19). Dysplasia was defined as unequivocal neoplasia of the epithelium confined to the basement membrane, without invasion into the lamina propia. The authors proposed classifying biopsy specimens into five categories: negative for dysplasia; indefinite for dysplasia; positive for low-grade dysplasia; high-grade dysplasia; or invasive cancer. In 1998, an alternative classification system for dysplasia in the gastrointestinal tract was developed with the hope that it would standardize terminology (20). The Vienna classification system is similar to the one proposed by Riddell et al (19) except that the former uses the term 'non-invasive neoplasia' instead of 'low- or high-grade dysplasia' and also uses the term 'suspicious for invasive carcinoma'. The Riddell classification is most commonly used.

Both United States and European guidelines recommend a conservative endoscopic resection strategy for localized polypoid lesions in selected patients $(13,21)$. When a dysplastic polyp (predicted by Kudo pit pattern) is detected within an area of inflammation in the colon in patients with IBD, this lesion can be removed safely by polypectomy and continued surveillance. It is not necessary to recommend colectomy in all patients, but it is strongly recommended to obtain biopsy specimens separately from areas of flat colitic mucosa surrounding the base of adenoma-like and non-adenoma-like DALMs. These should be clearly marked in the specimen bottle so that the pathologist can identify the exact sites of biopsies. Polyps within noncolitic areas may be removed using techniques similar to those used for sporadic polyps in non-IBD patients. With the novel endoscopic techniques, the margins of polypoid lesions can be assessed for abnormal pit pattern as well by expert endoscopists $(13,21)$. A designated colonoscopist for IBD patients in large centres may be appropriate to provide expertise in these challenging patients.

\section{ENDOSCOPIC SURVEILLANCE AND ITS LIMITATIONS}

Endoscopic surveillance programs are intended to detect premalignant change or malignancy at an early disease stage (22). The standard recommendation for surveillance colonoscopy in IBD is to perform colonoscopy yearly starting eight to 10 years after diagnosis of $\mathrm{UC}$ and to take random biopsies from each quadrant every $10 \mathrm{~cm}$. It has been demonstrated that 33 to 50 jumbo forceps biopsies may be needed to provide the highest yield of dysplasia or CRC with $90 \%$ confidence $(3,23)$. Extra biopsies should be obtained from strictured or raised areas and from other endoscopically abnormal areas detected in the colon, such as a change in colour.

However, despite this intensive regimen, surveillance colonoscopy with white-light (WL) endoscopy can often miss flat multifocal lesions and has not been shown to decrease CRC-related mortality in UC. Furthermore, a Cochrane systematic review (24) found no clear evidence that endoscopic surveillance improves survival among UC patients. Additionally, random biopsies may visualize $<1 \%$ of the total colonic mucosa surface area and can, thus, lead to a large sampling error. The number of biopsies taken during surveillance colonoscopy in IBD appear to increase the detection rate of dysplasia. Eaden et al $(25,26)$ demonstrated that the probability of detecting displasia was $90 \%$ if 33 biopsies were taken and this increased to $95 \%$ with 56 biopsies taken. In addition, there are considerable costs associated with processing and interpreting biopsy specimens. Finally, such a standard is logistically difficult and often not followed in real-life clinical practice, as shown in studies from the United Kingdom and Netherlands, where the majority of gastroenterologists did not follow the guidelines with regard to the number of biopsies (25-27). 
Recently, the European Crohn's and Colitis consensus statement recommended the use of chromoendoscopy to collect targeted biopsies of abnormal areas. The recommendation stated that methylene blue or indigo carmine chromoendoscopy is an alternative to random biopsies for appropriately trained endoscopists, and is superior to random biopsies in the detection of neoplastic lesions (28).

The surveillance strategy may be summarized as follows:

1. Ideally, surveillance colonoscopy should be performed on patients during clinical remission of disease to avoid confusing inflammatory changes with dysplasia (13).

2. However, if this is not possible and inflammatory changes are present, the procedure may be repeated after a period of medical therapy, such as steroids, in an attempt to induce remission (29). It is important to assess the biopsies for both inflammation and dysplasia. The pathologist should be given information about the endoscopic inflammatory score, such as Mayo subscore or simple endoscopic score-CD, so that the biopsies are considered in their appropriate inflammatory status context.

3. Surveillance colonoscopy should be started eight to 10 years after the onset of symptoms for patients with left-sided or extensive colitis as well as for CD-associated colitis.

4. Patients must undergo regular surveillance schedules after the initial colonoscopy.

5. Colonoscopic surveillance should be performed annually in patients with PSC following its diagnosis.

In addition, studies in non-IBD patients suggest that adenoma detection rate may be optimized by using antispasmodic drugs during colonoscopy $(30,31)$. This may be used in patients without contraindications. Withdrawal time may also be relevant in IBD patients for detecting neoplastic lesions, although no study has assessed this directly in this population.

\section{NOVEL ENDOSCOPIC TECHNIQUES}

Novel endoscopic techniques are summarized in Table 1.

Colonoscopic surveillance in patients with longstanding IBD is highly recommended and is the standard of care. The main objective of surveillance colonoscopy in UC is to detect neoplasia at an early stage amenable to endoscopic therapy or surgical cure, and preferably at the preinvasive stage.

Novel endoscopic techniques, including high-definition endoscopy, chromoendoscopy, virtual or electronic chromoendoscopy, autofluorescence imaging (AFI), confocal laser endomicroscopy (CLE) and endocytoscopy, have the potential to improve neoplasia detection rates and may contribute to reducing random biopsies by taking targeted biopsies for histological evaluation. High-definition endoscopy offers superior resolution to standard endoscopy and may significantly improve the detection and characterization of IEN in UC.

Conventional chromoendoscopy is the oldest and simplest method to improve the diagnosis of epithelial changes. Different dye solutions are applied to the mucosa of the gastrointestinal tract and can be classified as absorptive or contrast agents $(15,32)$. Absorptive agents include methylene blue $0.1 \%$ to $0.5 \%$ and cresyl violet $0.05 \%$. They are absorbed by different cells to different degrees, highlighting distinct cell types. Contrast agents, such as indigo carmine $0.2 \%$ to $0.4 \%$, coat the colonic mucosal surface and highlight tissue architecture because of the higher contrast of pooled dye within the small grooves between the colonic crypts and within the colonic pits. High-quality bowel cleansing is crucial for dye staining to enable meticulous evaluation of the mucosa (Table 2). Chromoendoscopy has two main goals (33). First, it improves the detection of subtle colonic lesions, increasing the sensitivity of the endoscopic examination. This is important in UC because flat dysplastic lesions can be difficult or impossible to detect with WL endoscopy. Second, once a lesion is detected, chromoendoscopy can improve characterization of lesions and margins, thus increasing the specificity of the examination. This can be further refined with magnifying and/or high-definition colonoscopes and has led to categorization of the different pit patterns in the colon. The Kudo classification (34), the international classification system commonly used, differentiates five types of pit patterns: types I and II are staining patterns predicting non-neoplastic lesions, whereas types III to $\mathrm{V}$ are predictive of neoplastic lesions. Several prospective, randomized trials using methylene blue or indigo carmine for panchromoendoscopy in patients with longstanding UC have shown the unique benefit of chromoendoscopy for the diagnosis of intraepithelial neoplasia (35). The first randomized controlled trial demonstrating a clear advantage for chromoendoscopy was published in 2003 by Kiesslich et al (36) in which significantly more neoplastic lesions were detected using this modality (32 versus 10 ). These data were subsequently corroborated in other randomized studies $(37,38)$. Hurlstone et al (38) also reported a significant increase in IEN detection rate with indigo carmine-assisted high-magnification chromoendoscopic colonoscopy compared with standard-definition endoscopy in UC patients. In a meta-analysis, chromoendoscopy had a sensitivity of $83.3 \%$ (95\% CI $35.9 \%$ to $99.6 \%$ ), a specificity of $91.3 \%$ (95\% CI $43.8 \%$ to $100 \%$ ) and diagnostic OR of 17.544 (95\% CI 1.245 to 247.14) (16). Recently, another meta-analysis showed that the difference in yield of dysplasia between chromoendoscopy and WL endoscopy was $7 \%$ (95\% CI $3.2 \%$ to $11.3 \%$ ) (35). The difference in proportion of lesions detected by targeted biopsies was 44\% (95\% CI $28.6 \%$ to $59.1 \%$ ) and flat lesions was $27 \%$ (95\% CI $11.2 \%$ to $41.9 \%$ ) in favour of chromoendoscopy. This demonstrates that chromoendoscopy has medium to high sensitivity and high diagnostic accuracy for neoplasia in UC compared with WL endoscopy.

However, chromoendoscopy has certain limitations: the mucosa is not always equally sprayed; areas of colourant pooling prevent proper visualization; it has additional cost; and, most importantly, it tends to be more time consuming (39). However, a recent study suggested that chromoendoscopy is both more effective and less costly than WL endoscopy (40). However, further studies are required with other novel endoscopic techniques to detect subtle lesions.

High-definition virtual chromoendoscopy, also called dye-less (or dye free) chromoendoscopy, is a recently introduced image enhancement technique that comprises different technologies incorporated into colonoscopes by different manufacturers: narrow-band imaging (NBI; Olympus, Japan), Fujinon Intelligent Color Enhancement (FICE; Fujinon, Japan) and iScan (Pentax, Japan). In a retrospective cohort study of patients with longstanding ( $>7$ years) colonic IBD undergoing surveillance colonoscopy, Subramanian et al (41) confirmed that highdefinition colonoscopy improved targeted detection of dysplastic lesions during surveillance colonoscopy compared with WL endoscopy. The adjusted prevalence ratio of detecting any dysplastic lesion and dysplastic lesion on targeted biopsy was 2.21 (95\% CI 1.09 to 4.45 ) and 2.99 (95\% CI 1.16 to 7.79 ), respectively, for high-definition colonoscopy.

NBI uses optical filters in front of the light source to narrow the wavelength of the projected light to $30 \mathrm{~nm}$ wide spectra of blue $(415 \mathrm{~nm})$ and green $(540 \mathrm{~nm})$, which enables a detailed examination of the mucosa and superficial vasculature. The role of NBI in detecting dysplasia in longstanding UC remains somewhat uncertain due to conflicting results in the literature. In a prospective randomized crossover study involving 42 patients with longstanding UC, Dekker et al (42) were the first to demonstrate that NBI does not improve the detection rate of neoplasia in UC compared with high-definition WL. A potential explanation was the chronic inflammation that possibly distorts the detection rate of IEN in UC. In the meantime, two other trials $(43,44)$ demonstrated that high-definition WL was equivalent to NBI. An additional study suggested that NBI offers no advantage over dye chromoendoscopy in IBD surveillance and NBI may not increase the detection rate of IEN in IBD (45).

These findings have led to controversy regarding the real role of NBI in dysplasia detection in UC patients. Pellisé et al (46) compared the new-generation NBI system with high-resolution imaging with dye chromoendoscopy for the early detection of colitis-associated dysplasia and cancer in patients with longstanding colonic IBD. 
TABLE 1

Studies of chromoendoscopy, autofluorescence imaging (AFI) and narrow-band imaging

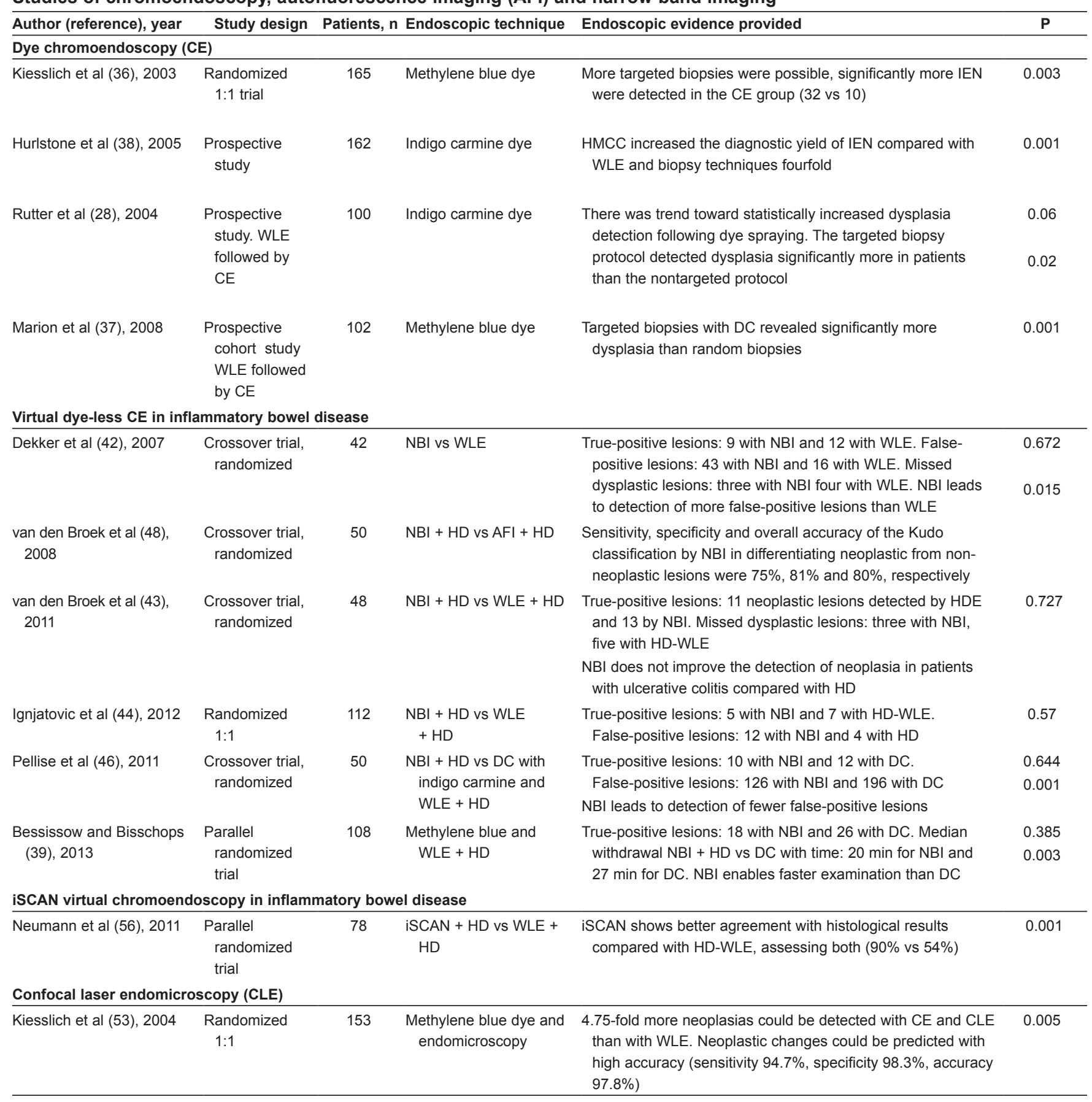

AFI Autofluorescence imaging; DC Dye chromoendoscopy; HD High-definition; HMCC High-magnification chromoscopic colonoscopy; IEN Intraepithelial neoplasia; iSCAN Pentax, USA; NBI Narrow-band imaging; LGD Low-grade dysplasia; vs Versus; WLE White-light endoscopy

NBI was reported to be a less time-consuming and equally effective modality compared with dye chromoendoscopy for detection of IEN. Withdrawal time was significantly longer with dye chromoendoscopy compared with NBI (46). Given the significant convenience of virtual chromoendoscopy over dye chromoendoscopy, further studies are required with new generation dye-less chromoendoscopy techniques.

AFI is another novel technique that uses short-wavelength (blue) light for excitation of endogenous tissue fluorophores that emit fluorescent light of longer wavelength. The AFI endoscope has two separate charge-coupled devices for WL endoscopy and AFI. Recently, high-resolution WL endoscopy, AFI and NBI have been incorporated into one system known as endoscopic trimodal imaging.
A button on the endoscope enables switching between WL endoscopy, AFI and NBI. The resultant images show normal mucosa as green and dysplastic/cancerous tissue as magenta in colour. The early experience with such trimodal imaging for the detection and differentiation of colonic polyps was not encouraging (47).

Initial pilot studies suggested that AFI could be useful in the detection of dysplasia at surveillance colonoscopy for patients with UC. A subsequent randomized colonoscopy trial showed that AFI improves the detection rate of neoplasia in patients with UC and decreases the yield of random biopsies.

The miss rates for neoplasia for AFI and WL endoscopy were $0 \%$ and $50 \%$, respectively $(\mathrm{P}=0.036)$. However, the miss rate for $\mathrm{WL}$ 
TABLE 2

Optimization strategy of surveillance in inflammatory bowel disease (IBD)

- Have optimal bowel preparation: the entire bowel mucosa should be without mucus, pus or stool

- Surveillance colonoscopy should be performed in patients with minimal or no inflammation

- Withdrawal time and antispasmodic agents have been shown to be associated with improved adenoma detection in noncolitis patients (likely the same in IBD surveillance) (Corte 2012 [30])

- Use two ampules of indigo carmine $8 \mathrm{mg} / \mathrm{mL}(5 \mathrm{~mL})$ or one ampule of methylene blue $10 \mathrm{mg} / \mathrm{mL}(10 \mathrm{~mL})$ in $250 \mathrm{~mL}$ of saline throughout the water jet channel using the pump

- On visualization of the lesion, spray indigo carmine $0.2 \%$ or methylene blue $0.1 \%$ to better characterize mucosal pattern and edges of the lesions

- Resect and snare circumscribed lesion

endoscopy was unusually high in this study and the encouraging detection rate for neoplasia in UC needs to be confirmed in further studies (48).

Both FICE and iSCAN are based on a physical principle similar to NBI, but instead of optical filters inside the video endoscope, they are dependent on a computed spectral estimation technology that develops endoscopic images from the video processor and reconstructs virtual images in real time by increasing the intensity of narrowed blue light to a maximum, and by decreasing narrowed red and green light to a minimum.

iSCAN has three modes of image enhancement (49): surface enhancement, contrast enhancement and tone enhancement. iSCAN may be a promising technique to differentiate neoplastic from nonneoplastic lesions of the colon. Hoffman et al (50) tested the efficacy of high-definition endoscopy alone compared with i-SCAN or chromoendoscopy with methylene blue $0.1 \%$ in screening for dysplasia and CRC. They demonstrated that both iSCAN and chromoendoscopy identified more lesions compared with high-definition endoscopy alone. iSCAN was also able to predict neoplasia as precisely as chromoendoscopy, with an accuracy of $89 \%$ to $97 \%$.

In a prospective, randomized, back-to-back trial evaluating the usefulness of iSCAN in screening colonoscopy, Hong et al (51) recently demonstrated that iSCAN during the screening colonoscopy may fail to improve adenoma detection and the prevention of missed polyps. However, iSCAN appears to be effective for real-time histological prediction of polyp pathology compared with conventional high-definition WL colonoscopy (51). However, more randomized studies are needed to confirm these results before iSCAN can be considered to be an alternative to dye-spraying chromoendoscopy in the context of IBD surveillance (Figure 1).

CLE is a novel endoscopic imaging technique that provides in vivo histology during ongoing endoscopy (52). CLE offers in vivo imaging of the mucosal layer at celullar and even subcellular resolution. CLE can currently be performed with two different endoscopic modalities. First, a miniaturized confocal scanner has been integrated into the distal tip of a flexible endoscope (Pentax, Japan) (53). Second is the use of confocal microscopy miniprobes (54) (pCLE, Cellvizio, Mauna Kea Technologies, France). These probes can be fitted through the working channel of standard endoscopes. The functional principle relies on the delivery of blue laser light to mucosal tissue, which translates into an excitation wavelength of $488 \mathrm{~nm}$ and light emission detection at $505 \mathrm{~nm}$. When the mucosa is scanned, serial optical sections are constructed. The end-result images are approximately a 1000-fold magnification of in vivo tissue (53).

CLE requires the use of fluorescent agents. Most studies involving humans have been performed using $10 \mathrm{~mL}$ of intravenous $5 \%$ fluorescein sodium. Fluorescein quickly distributes within all compartments of the tissue and CLE is possible within seconds after injection. It contrasts cellular and subcellular details, connective tissue and vessel architecture at high resolution but does not stain nuclei (55).

Kiesslich et al (52) demonstrated that chromoendoscopy, in combination with CLE, enabled a significant increase in the diagnostic yield of IEN. In the CLE group, circumscribed lesions were identified

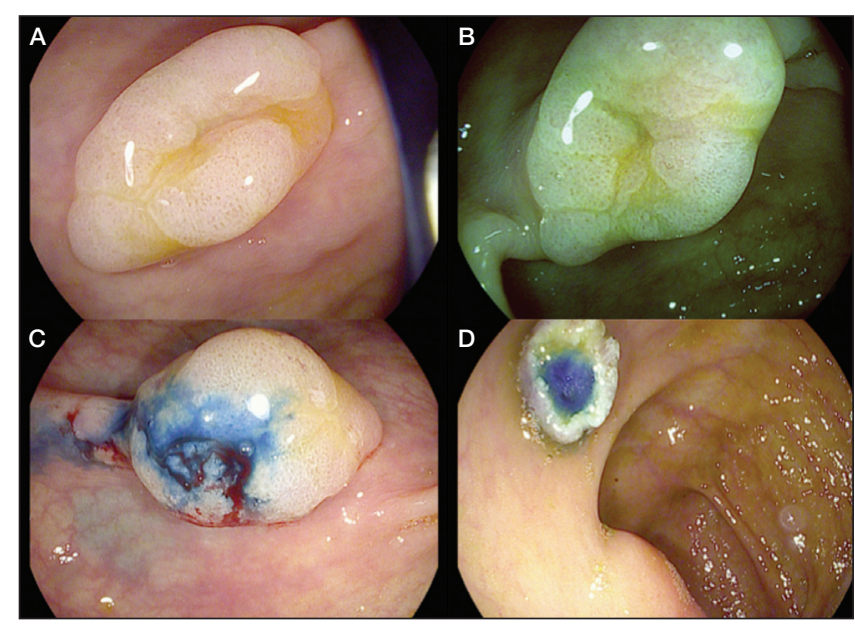

Figure 1) A High-definition iSCAN (Pentax, Japan) technique showing a flat lesion in the ascending colon. B and C iSCAN virtual chromoendoscopy characterized the margins of the lesion and the Kudo pit pattern of the mucosa as type II open and irregular spiral vascular pattern. D Endoscopic mucosal resection after previous injection of saline and methylene blue was performed. Serrated adenoma was reported by histology

by chromoendoscopy and evaluated for targeted biopsy examination by CLE. The presence of IEN was predicted with a sensitivity of $94.7 \%$ and a specificity of $98.3 \%$. The combined use of chromoendoscopy with CLE reduced the number of biopsies compared with conventional colonoscopy to 3.9 biopsies per patient instead of 40 to 50 , and demonstrated a $>4$-fold increased diagnostic yield for IEN (Figures 2 and 3).

\section{Endocytoscopy}

Endocystoscopy is a recent and evolving endoscopic imaging technique that enables detailed examination of the mucosal surface through systems integrated in the distal tip of the endoscope or through a probe-based system. This technique provides up to 1400 fold magnification of the mucosa. The concept behind endocystoscopy is based on a contact light microscope that enables real-time visualization of cellular structures of the superficial epithelial layer. Topical application of an absorptive contrast agent is required. No data are currently available on the use of endocystoscopy in surveillance colonoscopy in IBD, but it has been shown to be useful for the distinction between neoplastic and non-neoplastic tissues in the colon and avoiding unnecessary polypectomy $(56,57)$. Further studies are needed in IBD.

\section{NOVEL ENDOSCOPIC THERAPEUTIC STRATEGIES} IN IBD SURVEILLANCE - ENDOSCOPIC RESECTION

The appropriate management of IEN in IBD is evolving with advances in endoscopic technology. Lesion resectability is now the most important characteristic influencing the decision to either continue endoscopic surveillance or recommend colectomy in IBD patients. More 


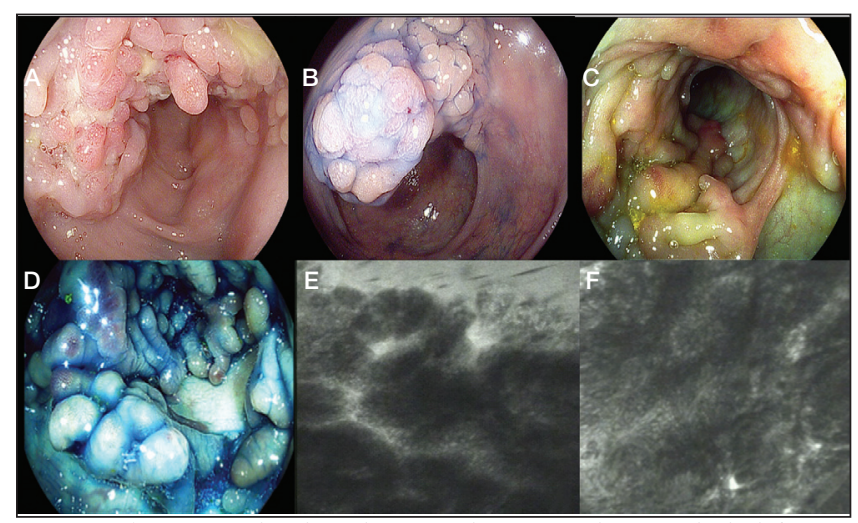

Figure 2) A pseudopolypoid mass characterized using high-definition iSCAN (Pentax, Japan) technique. B High-definition dye chromoendoscopy with indigo carmine $0.2 \%$ showing mucosal pit pattern type II non neoplastic. C and D Segmental area of pseudopolyp characterized using iSCAN virtual chromoendoscopy and in combination with dye indigo carmine chromoendoscopy. E and $\mathrm{F}$ Endomicroscopy appearance according to confocal laser endomicroscopy and fluorescein $5 \mathrm{~mL} \mathrm{10 \% .} \mathrm{E} \mathrm{Polypoid}$ inflamed mucosa with proliferative and distorted glands/crypts. F Polypoid granulation tissue with no remaining glands

recent studies have suggested that these lesions are heterogeneous and not all subtypes may be strongly associated with progression to malignancy. Circumscribed raised lesions and sporadic adenomas, with a sessile or pedunculated gross appearance, may be safely removed using polypectomy despite occurring in patients with UC. Polypectomy may be adequate treatment for adenoma-like dysplastic lesions in chronic $\mathrm{UC}(17,58)$.

Several studies have demonstrated that endoscopic surveillance is a safe and effective approach to the management of patients who have visible circumscribed neoplastic lesions resected during surveillance endoscopy $(17,59)$. Hurlstone et al (59) evaluated 712 UC patients who underwent neoplasia surveillance with pancolonic chromoendoscopy and also had interval random biopsy specimens. One hundred thirty-two circumscribed noninvasive neoplasms were resected during index colonoscopy, including 46 raised lesions, 79 flat lesions and seven laterally spreading tumours, 18 of which harboured high-grade IEN. No subsequent CRC or flat IEN developed in any patients in this group throughout the study period with a median follow-up period of 3.8 years. This underscores the importance of considering colectomy as a treatment strategy in patients with flat IEN discovered in random biopsy specimens.

However, Kisiel et al (60) also showed that polypectomy may be safe for the management of adenomas occurring in most UC patients; the five-year cumulative incidence of cancer or flat dysplasia was $13 \%$. Such patients should be able to avoid colectomy but need to be followed closely (Figure 3).

Further studies using these novel endoscopic techniques are necessary to confirm the safety of polypectomy and EMR in patients with irregular DALM lesions or lesions with high-grade IEN.

\section{SERRATED ADENOMAS IN IBD: AN EMERGING PROBLEM}

There is emerging evidence that serrated adenomas are also associated with longstanding IBD colitis and have become recognized as another important contributory factor to CRC developement. Sessile serrated adenomas are considered to be preneoplastic lesions, even if these do not show dysplasia at histology. The terminology in the context of IBD has not been fully clarified. Several articles use the terms 'serrated adenoma' and 'dysplasia' concurrently. Unfortunately, they are often subtle in appearance at endoscopy and pose challenges for endoscopic detection and removal, especially in colitic mucosa (Figure 1). Rubio

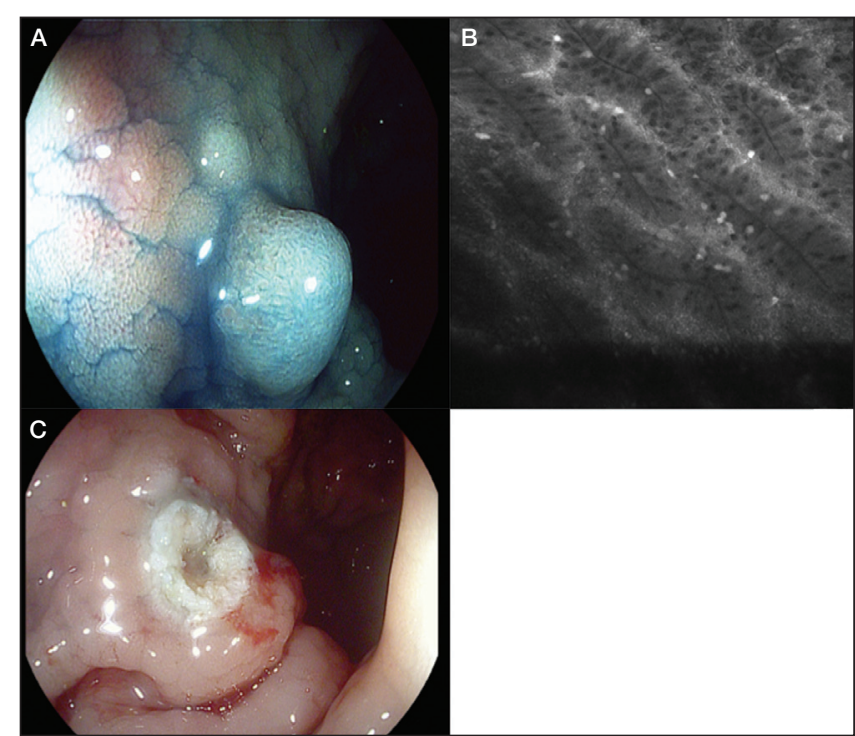

Figure 3) A High-definition iSCAN (Pentax, Japan) in combination with dye chromoendoscopy (indigo carmine $0.2 \%$ ) showing adenoma-like mass with Kudo pit pattern type III L. B Confocal laser endomicroscopy with fluorescein (5 mL 10\%) confirmed the diagnosis of adenoma. C Endoscopic resection, adenoma was reported by histology

et al (61) assessed the histological phenotype of the dysplastic lesion juxtaposing colorectal carcinomas in 100 consecutive colectomy specimens (50 patients with IBD and in 50 controls [non-IBD patients]). They reported that the majority ( $81.2 \%$ [31 of 38]) of the dysplastic lesions juxtaposing IBD carcinomas were villous or serrated adenoma but only $55.1 \%$ (16 of 29) in control cases. Serrated adenoma in particular accounted for nearly $29 \%$ of the noninvasive dysplastic lesions arising in IBD carcinomas but only for 3\% in control specimens. Recent findings suggest that the BRAF V600E mutation is a specific marker for the serrated pathway originating from an hyperplastic polyp (62).

Chaubert et al (63) and Bossard et al (64) characterized the molecular status of the serrated neoplasia pathway in IBD based on the determination of BRAF and KRAS mutations, the MMR deficiency status as assessed by immunohistochemistry and the MSI status. They demonstrated high sensitivity of the activating BRAF V600E mutation as a biomarker for the serrated neoplasia pathway in inflammatory bowel disease. It was identified in all serrated preneoplastic lesions and in the MSI mucinous adenocarcinoma of the right colon, and was not found in any of the histological categories of the traditional adenomacarcinoma sequence. KRAS mutations are observed preferentially in these traditional lesions, as in sporadic colorectal oncogenesis, and have been intensively studied throughout the inflammatory/regenerative/ dysplasia/cancer sequence in IBD.

\section{ESD IN IBD: A DREAM OR REALITY?}

Endoscopic resection of an adenoma-like DALM in chronic UC is often difficult because it is complicated by submucosal fibrosis.

ESD is a new advance in minimally invasive therapeutic endoscopy, with a major advantage in achieving a higher en bloc resection rate and more accurate in histopathological assessment and enhanced curability. ESD was developed in Japan in the mid-1990s to resect early stage gastric cancers en bloc. Colonic ESD techniques were developed in Japan and the techniques have been described in detail (65).

ESD is now widely performed in the colorectum in East Asian countries, especially Japan (66). In contrast, Western endoscopists infrequently perform coloretal ESD (CR-ESD) despite some of its 
major advantages. There are several reasons that may explain this difference. First, ESD has multiple technical challenges related to the anatomical features of the colon (compared with the stomach) including its longer length, narrower lumen, extensive flexion and thinner walls, longer procedure time and increased risk of perforation.

Therefore, specialized training and adequate clinical experience appear to be necessary to acquire a satisfactory and high level of skill for performing ESD. Additionally, there has been a lack of dedicated instruments for ESD in the West, and the choice of devices for ESD available in North America is different compared with those available in Japan $(67,68)$. However, CR-ESD is also starting to become adopted in North America (69).

The safety and efficacy of CR-ESD for large colorectal lesions has recently been reported in a systematic review (70), and we have recently reviewed CR-ESD techniques and the feasibility of application in the West (71). CR-ESD is not considered to be advanced medical care eligible for national health insurance coverage, and the cost of this procedure has not yet been covered by Western national health insurance or private payers. Further pharmacoeconomic studies need to be performed to determine the cost-benefit of such an approach (69).

ESD can result in successful en bloc resections even for lesions with submucosal fibrosis involving DALM because endoscopists are able to directly visualize the submucosal layer. In fact, a highly experienced endoscopist demonstrated an excellent curative resection of colorectal ESDs with various devices and accessories for residual/local recurrence of epithelial lesions following endoscopic resection that had severe fibrosis into the submucosal layer $(72,73)$. ESD in Crohn's colitis may be more problematic due to the transmural nature of involvement and frequent fibrosis.

Presently, there are no data to guide when to use EMR and when to use ESD in the context of IBD surveillance. Smaller lesions $(\leq 2 \mathrm{~cm})$ may be generally treated with snare for polypoid lesions and EMR for sessile or flat lesions permitting en bloc resection. In IBD, the flat margins around a polypoid lesion must be negative for dysplasia at histology (Figure 4A). Larger lesions with higher risks for residual neoplasia on piecemeal resection and superficial submucosal invasion are candidates for ESD, especially for the colonic lesions in patients with $\mathrm{CD}$ in which colectomy will result in permanent ileostomy. Whether very limited dysplasia around a well-defined lesion can be resected by ESD remains to be studied in IBD patients. However, multifocal lesions or ill-defined lesions will still require panproctocolectomy.

Patients with UC with a non-adenoma-like DALM represented by indistinct lesion border should be treated with colectomy because of the high association with dysplasia in flat mucosa adjacent and with metachronous or synchronous carcinoma.

In contrast, adenoma-like DALMs may be treated conservatively by complete endoscopic resection followed by confirmation of an absence of dysplasia at the margin of the specimen and continued surveillance without surgical intervention according to recent data $(13,74)$. However, ESD can demonstrate the lesion margin adequately. Endoscopic differentiation diagnosis of ALM and UC-related DALM in UC is also controversial and challenging (75). An accurate histological evaluation after complete endoscopic removal is required for the treatment of such lesions. Several investigators have sought to identify molecular and nonmolecular markers that may aid in the distinction of truly dysplastic from regenerating epithelium in UC $(76,77)$.

ESD may not be technically feasible for inexperienced endoscopists. ESD-assisted EMR, a so-called 'hybrid technique', was performed in 69 patients with selected lesions associated with UC (78). The endoscopic resection of ALM was technically feasible using the combination technique and was also curable. In fact, no metachronous circumscribed IEN lesions or cancer were detected at a median followup period of 18 months. Overall cure rates for the ESD-assisted EMR cohort was $98 \%$ (78). There was a limitation of selection bias of target

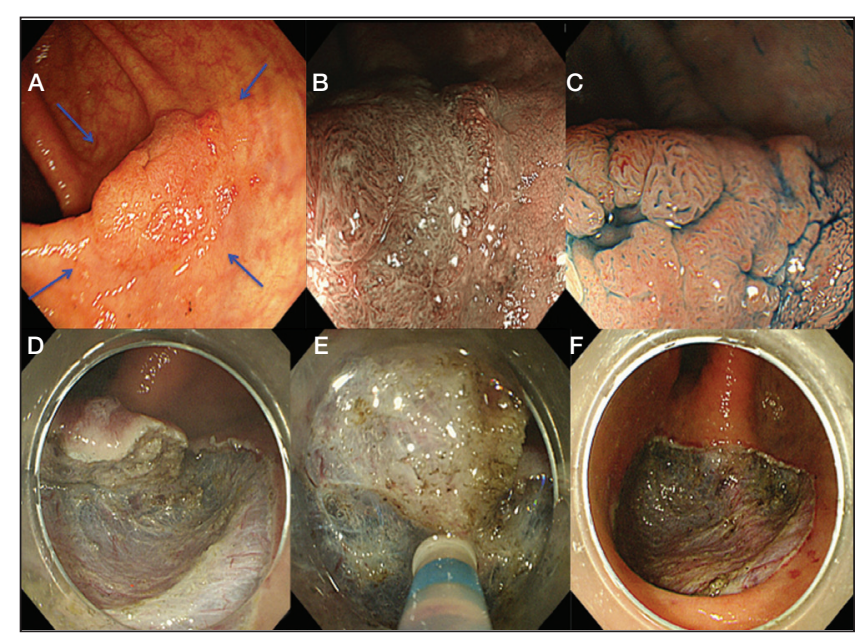

Figure 4) A A $2 \mathrm{~cm}$ 0-II lesion located in the ascending colon. B Narrowband imaging with magnification revealed type IIIA capillary pattern. C Indigo-carmine dye with magnification demonstrated type IIIL pit pattern. $\mathrm{D}$ to $\mathrm{F}$ Endoscopic submucosal dissection performed using dual knife. $\mathrm{F}$ Ulcer bed after en-bloc resection. Biopsies were taken for each quadrant around the lesions because it is colitic mucosa with high risk of multifocal dysplasia (blue arrows)

lesions for this technique. As far as we have experienced with a large number of CR-ESDs, EMR, even as the final step in the hybrid technique, is not technically easy and there remain issues of higher risk for large perforation. We fully recommend an ESD procedure for such lesions performed by highly experienced endoscopists to achieve en bloc resection (Figure 4).

The role of ESD may become important in future for management of neoplasia in UC patients.

\section{PROPOSED ENDOSCOPIC DIAGNOSTIC AND THERAPEUTIC STRATEGY FOR NEOPLASIA SURVEILLANCE AND MANAGEMENT IN IBD - CAN WE SAVE THE COLON IN SELECTED PATIENTS?}

High-definition dye chromoendoscopy technique with targeted biopsies may represent the first choice in surveillance of longstanding colitis in IBD. High-definition virtual chromoendoscopy as an alternative requires further study. A combination of CLE with chromoendoscopy with indigo carmine $0.2 \%$ may represent an additional option in tertiary centres for high-risk IBD patients who develop cancer such as patients with PSC, low-grade or high-grade IEN or dysplasia, or presence of DALM or serrated adenoma. The optimum endoscopic approach is illustrated schematically including concentrations of indigo carmine and methylene blue (Figure 5).

Targeted neoplasia screening with high-definition iSCAN, FICE or NBI pancolonic endoscopy with virtual chromoendoscopy may provide a number of benefits including convenience, quicker procedures and the capability of on-off virtual chromoendoscopy. However, pancolonic dye chromoendoscopy has been proven to be efficacious in increasing the yield of dysplasia in IBD patients and to reduce the number of biopsies. It remains controversial whether the other novel endoscopic techniques described above can be used alone in routine surveillance colonoscopy in IBD. Many further well-designed studies are required to determine whether dye chromoendoscopy can be replaced by high-definition imaging with novel endoscopic techniques. Well-demarcated neoplastic flat lesions without features of submucosal invasion need first to be characterized in detail using dye spray such as indigo carmine $0.4 \%$ or methylene blue $0.2 \%$ (highly irregular surface mucosal pit pattern, mucosal depression, radiating mucosal folds, insufflation-desufflation deformity or failure of the 


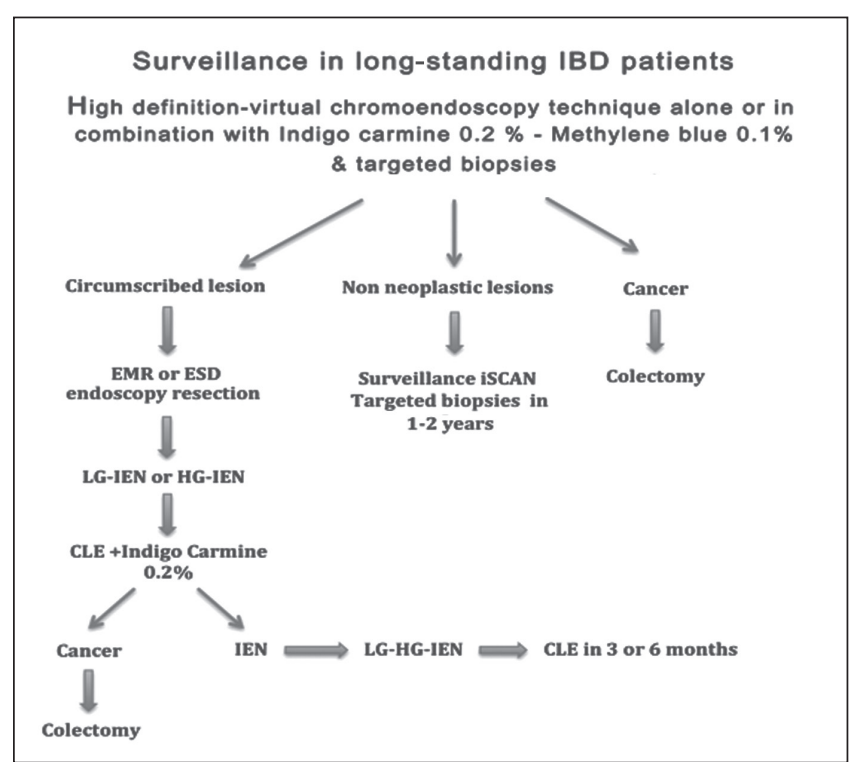

Figure 5) Flow chart illustrating the proposed strategy for surveillance and management of dysplasia in inflammatory bowel disease (IBD). CLE Confocal laser endoscopy; ESD Endoscopic submucosal dissection; EMR Endoscopic mucosal resection; HG-IEN High-grade intraepithelial neoplasia; LG-IEN Low-grade intraepithelial neoplasia

lesion to lift with submucosal saline injection). These may then be resected endoscopically using EMR or ESD techniques if possible, and these patients should, of course, continue in an endoscopic surveillance program. Patients with incompletely resected lesions or those who have lesions with histological dysplasia or invasive carcinoma should undergo histological evaluation by a second experienced gastrointestinal pathologist before undergoing colectomy. American Society for Gastrointestinal Endoscopy guidelines suggested that the presence of high-grade IEN and multifocal low-grade IEN in flat muocosa is an indication for colectomy (74).

We propose that patients with low-grade IEN undergo surveillance within three to six months by an experienced endoscopist with high-definiton virtual chromoendoscopy, preferably in combination with pancolonic chromoendoscopy with indigo carmine and CLE following meticulous bowel cleansing and/or treatment of inflammation (Figure 5).

Finally, particular attention should be devoted to diffuse or segmental mass pseudopolyps (inflammatory polyps) associated with IBD, which appear to be an additional risk factor or marker for IBD-CRC, while in themselves having no malignant potential. It is not clear whether this increased risk is due to a higher miss rate of dysplastic polyps difficult to distinguish from the benign pseudopolyps during surveillance colonoscopies or due to the fact that pseudopolyps are a historical marker of more severe inflammation (79). Unfortunately, this is an area of uncertainty and no studies have been performed to guide on how best to perform surveillance in these patients. This will be an interesting and unexplored area of future research. In our experience, we perform surveillance colonoscopy with high-definition iScan virtual chromoendoscopy in combination with dye chromoendoscopy with indigo carmine $0.2 \%$. We optimize the settings of surface, contrast and tone enhancement of high-definition iScan to maximize the quality of the image and to better characterize the neoplastic Kudo pit pattern and target biopsies (Figure 2). It is generally not advisable to attempt resection of inflammatory pseudopolyps because these usually regrow. With careful inspection, Kudo pit patterns may distinguish neoplastic from inflammatory areas.

\section{SUMMARY}

The clinicopathological link between IBD and CRC is well established and provides the rationale for endoscopic surveillance. This field is rapidly evolving with high-definition endoscopic technologies. These novel techniques have the potential to replace dyespraying chromoendoscopy for detection of dysplasia, but prospective studies are required. Additionally, they have the potential to reveal detailed characterization of the lesions and enable endoscopic targeting of biopsies. Furthermore, techniques such as endoscopic submucosal resection may spare a colectomy in highly selected patients. This possibility requires very careful characterization of lesions with novel endoscopic techniques. Increasingly dedicated specialized endoscopists with IBD interest are necessary to fully exploit these evolving technologies and lead prospective studies.

DISCLOSURES: The authors have no financial disclosures or conflicts of interest to declare.

\section{REFERENCES}

1. Eaden JA, Abrams KR, Mayberry JF. The risk of colorectal cancer in ulcerative colitis: A meta-analysis. Gut 2001;48:526-35.

2. Beaugerie L, Svrcek M, Seksik P, et al. Risk of colorectal high-grade dysplasia and cancer in a prospective observational cohort of patients with inflammatory bowel disease. Gastroenterology 2013;145:166-75.

3. Loftus EV Jr. Epidemiology and risk factors for colorectal dysplasia and cancer in ulcerative colitis. Gastroenterol Clin North Am 2006;35:517-31.

4. Jess T, Simonsen J, Jørgensen KT, et al. Decreasing risk of colorectal cancer in patients with inflammatory bowel disease over 30 years. Gastroenterology 2012;143:375-81.

5. Stolfi C, Pellegrini R, Franze E, et al. Molecular basis of the potential of mesalazine to prevent colorectal cancer. World J Gastroenterol 2008;14:4434-9.

6. Andersen NN, Jess T. Has the risk of colorectal cancer in inflammatory bowel disease decreased? World J Gastroenterol 2013;43:7561-8.

7. Rubin DT, Huo D, Kinnucan JA, et al. Inflammation is an independent risk factor for colonic neoplasia in patients with ulcerative colitis: A case-control study. Clin Gastroenterol Hepatol 2013;11:1601-8.

8. Soetikno RM, Lin OS, Heidenreich PA, et al. Increased risk of colorectal neoplasia in patients with primary sclerosing cholangitis and ulcerative colitis: A meta-analysis. Gastrointest Endosc 2002;56:48-54.

9. Kaplan GG, Heitman SJ, Hilsden RJ, et al. Population-based analysis of practices and costs of surveillance for colonic dysplasia in patients with primary sclerosing cholangitis and colitis. Inflamm Bowel Dis 2007;13:1401-7.

10. Jess T, Gamborg M, Matzen P. Increased risk of intestinal cancer in Crohn's disease: A meta-analysis of population-based cohort studies. Am J Gastroenterol 2005;100:2724-9.

11. Canavan C, Abrams KR, Mayberry J, et al. Meta-analysis: Colorectal and small bowel cancer risk in patients with Crohn's disease. Aliment Pharmacol Ther 2006;23:1097-104.

12. Lutgens MW, van Oijen MG, van der Heijden GJ, et al. Declining risk of colorectal cancer in inflammatory bowel disease: An updated meta-analysis of population-based cohort studies. Inflamm Bowel Dis 2013;19:789-99.

13. Farraye FA, RD, Odze RD, Eaden J, et al. AGA Medical position statement on the diagnosis and management of colorectal neoplasia in inflammatory bowel disease. Gastroenterology 2010;138:738-45.

14. Ullman T, Croog V, Harpaz N, et al. Virtually all CRC develop from dysplastic precursor lesions. Gastroenterology 2003;25:1311-9.

15. Itzkowitz SH, Harpaz N. Diagnosis and management of dysplasia in patients with inflammatory bowel diseases. Gastroenterology 2004;126:1634-48.

16. Rutter M, Bernstein C, Matsumoto T, et al. Endoscopic appearance of dysplasia in ulcerative colitis and the role of staining. Endoscopy 2004;36:1109-14. 
17. Rubin PH, Friedman S, Harpaz N, et al. Colonoscopic polypectomy in chronic colitis: Conservative management after endoscopic resection of dysplastic polyps. Gastroenterology 1999;117:1295-300.

18. Schneider A, Stolte M. Differential diagnosis of adenomas and dysplastic lesions in patients with ulcerative colitis. Z Gastroenterol 1993;31:653-6.

19. Riddell RH, Goldman H, Ransohoff DF, et al. Dysplasia in inflammatory bowel disease: Standardized classification with provisional clinical applications. Hum Pathol 1983;14:931-68.

20. Schlemper RJ, Riddell RH, Kato Y, et al. The Vienna classification of gastrointestinal epithelial neoplasia. Gut 2000;47:251-5.

21. Mowat C, Cole A, Windsor A, et al. Guidelines for the management of inflammatory bowel disease in adults. Gut 2011;60:571-607.

22. Efthymiou M, Taylor AC, Kamm MA. Cancer surveillance strategies in ulcerative colitis: The need for modernization. Inflamm Bowel Dis 2011;17:1800-13.

23. Jess T, Loftus EV Jr, Velayos FS, et al. Risk of intestinal cancer in inflammatory bowel disease: A population-based study from Olmsted County, Minnesota. Gastroenterology 2006;130:1039-46.

24. Collins PD Mpofu C, Watson AJ, et al. Strategies for detecting colon cancer and/or dysplasia in patients with inflammatory bowel disease. Cochrane Database Syst Rev 2006;CD000279.

25. Eaden J, Abrams K, Ekbom A, et al. Colorectal cancer prevention in ulcerative colitis: A case-control study. Aliment Pharmacol Ther 2000;14:145-53.

26. Eaden JA, Ward BA, Mayberry JF. How gastroenterologists screen for colonic cancer in ulcerative colitis: An analysis of performance. Gastrointest Endosc 2000;51:123-8.

27. Obrador A, Ginard D, Barranco L. Review article: Colorectal cancer surveillance in ulcerative colitis - what should we be doing? Aliment Pharmacol Ther 2006;24:56-63.

28. Rutter MD, Saunders BP, Schofield G, et al. Pancolonic indigo carmine dye spraying for the detection of dysplasia in ulcerative colitis. Gut 2004;53:256-60.

29. Baars JE, Vogelaar L, Wolfhagen FH, et al. A short course of corticosteroids prior to surveillance colonoscopy to decrease mucosal inflammation in inflammatory bowel disease patients: Results from a randomized controlled trial. J Crohns Colitis 2010;4:661-8.

30. Corte C, Dahlenburg L, Selby W, et al. Hyoscine butylbromide administered at the cecum increases polyp detection: A randomized double-blind placebo-controlled trial. Endoscopy 2012;44:917-22.

31. East JE, Stavrindis M, Thomas-Gibson S, et al. A comparative study of standard vs. high definition colonoscopy for adenoma and hyperplastic polyp detection with optimized withdrawal technique. Aliment Pharmacol Ther 2008;28:768-76.

32. Kiesslich R, MF Neurath. Chromoendoscopy and other novel imaging techniques. Gastroenterol Clin North Am 2006;35:605-19.

33. Kiesslich R, Neurath MF. Chromoendoscopy in inflammatory bowel disease. Gastroenterol Clin North Am 2012;41:291-302.

34. Kudo S, Tamura S, Nakajima T, et al. Diagnosis of colorectal tumorous lesions by magnifying endoscopy. Gastrointest Endosc 1996;44:8-14.

35. Subramanian V, Mannath J, Ragunath K, et al. Meta-analysis: The diagnostic yield of chromoendoscopy for detecting dysplasia in patients with colonic inflammatory bowel disease. Aliment Pharmacol Ther 2011;33:304-12.

36. Kiesslich R, Fritsch J, Holtmann M, et al. Methylene blue-aided chromoendoscopy for the detection of intraepithelial neoplasia and colon cancer in ulcerative colitis. Gastroenterology 2003;124:880-8.

37. Marion JF, Waye JD, Present DH, et al. Chromoendoscopy-targeted biopsies are superior to standard colonoscopic surveillance for detecting dysplasia in inflammatory bowel disease patients: A prospective endoscopic trial. Am J Gastroenterol 2008;103:2342-9.

38. Hurlstone DP, Sanders DS, Lobo AJ, et al. Indigo carmine-assisted high-magnification chromoscopic colonoscopy for the detection and characterisation of intraepithelial neoplasia in ulcerative colitis: A prospective evaluation. Endoscopy 2005;37:1186-92.

39. Bessissow T, Bisschops R. Advanced endoscopic imaging for dysplasia surveillance in ulcerative colitis. Expert Rev Gastroenterol Hepatol 2013;7:57-67.

40. Konijeti GG, Shrime MG, Ananthakrishnan AN, et al. Cost-effectiveness analysis of chromoendoscopy for colorectal cancer surveillance in patients with ulcerative colitis. Gastrointest Endosc 2013;S0016-5107.
41. SubramanianV, Ramappa V, Telakis E, et al. Comparison of high definition with standard white light endoscopy for detection of dysplastic lesions during surveillance colonoscopy in patients with colonic inflammatory bowel disease. Inflamm Bowel Dis 2013;19:350-5.

42. Dekker E, van den Broek FJ, Reitsma JB, et al. Narrow-band imaging compared with conventional colonoscopy for the detection of dysplasia in patients with longstanding ulcerative colitis. Endoscopy 2007;39:216-21.

43. van den Broek FJ, Fockens P, van Eeden S, et al. Narrow-band imaging versus high-definition endoscopy for the diagnosis of neoplasia in ulcerative colitis. Endoscopy 2011;43:108-15.

44. Ignjatovic A, East JE, Subramanian V, et al. Narrow band imaging for detection of dysplasia in colitis: A randomized controlled trial. Am J Gastroenterol 2012;10:885-90.

45. Efthymiou M, Allen PB, Taylor AC, et al. Chromoendoscopy versus narrow band imaging for colonic surveillance in inflammatory bowel disease.Inflamm Bowel Dis 2013;19:2132-8.

46. Pellisé M, López-Cerón M, Rodríguez de Miguel C, et al. Narrow-band imaging as an alternative to chromoendoscopy for the detection of dysplasia in long-standing inflammatory bowel disease: A prospective, randomized, crossover study. Gastrointest Endosc 2011;74:840-8.

47. van den Broek FJ, Fockens P, Van Eeden SE, et al. Clinical evaluation of endoscopic trimodal imaging for the detection and differentiation of colonic polyps. Clin Gastroenterol Hepatol 2009; 7:288-95.

48. van den Broek FJ, Fockens P, van Eeden S, et al. Endoscopic trimodal imaging for surveillance in ulcerative colitis: Randomised comparison of high-resolution endoscopy and autofluorescence imaging for neoplasia detection; and evaluation of narrow-band imaging for classification of lesions. Gut 2008;57:1083-9.

49. Kodashima S, Fujishiro M. Novel image-enhanced endoscopy with i-SCAN technology. World J Gastroenterol 2010;16:1043-9.

50. Hoffman A, Kagel C, Goetz M, et al. Recognition and characterization of small colonic neoplasia with high-definition colonoscopy using i-SCAN is as precise as chromoendoscopy. Dig Liver Dis 2010;42:45-50.

51. Hong SN, Choe WH, Lee JH, et al. Prospective, randomized, backto-back trial evaluating the usefulness of $\mathrm{i}$-SCAN in screening colonoscopy. Gastrointest Endosc 2012;75:1011-21.

52. Kiesslich R, Goetz M, Lammersdorf K, et al. Chromoscopy-guided endomicroscopy increases the diagnostic yield of intraepithelial neoplasia in ulcerative colitis. Gastroenterology 2007;132:874-82.

53. Kiesslich R, Burg J, Vieth M, et al. Confocal laser endoscopy for diagnosing intraepithelial neoplasias and colorectal cancer in vivo. Gastroenterology 2004;127:706-13.

54. Wallace MB, Fockens P. Probe-based confocal laser endomicroscopy. Gastroenterology 2009;36:1509-13.

55. Wallace M.B, Meining A, Canto MI, et al. The safety of intravenous fluorescein for confocal laser endomicroscopy in the gastrointestinal tract. Aliment Pharmacol Ther 2010;31:548-52.

56. Neumann H, Vieth M, Neurath MF. Image of the month. Endocytoscopy-based detection of focal high-grade intraepithelial neoplasia in colonic polyps. Clin Gastroenterol Hepatol 2011;9:13.

57. Kudo SE, Wakamura K, Ikehara N, et al. Diagnosis of colorectal lesions with a novel endocytoscopic classification - a pilot study Endoscopy 2011:43:869-75.

58. Pekow JR. Hetzel JT, Rothe JA, et al. Outcome after surveillance of low-grade and indefinite dysplasia in patients with ulcerative colitis. Inflamm Bowel Dis 2010;16:1352-6.

59. Hurlstone DP, Sanders DS, Atkinson R, et al. Endoscopic mucosal resection for flat neoplasia in chronic ulcerative colitis: Can we change the endoscopic management paradigm? Gut 2007;56:838-46.

60. Kisiel JB, Loftus EV Jr, Harmsen WS, et al. Outcome of sporadic adenomas and adenoma-like dysplasia in patients with ulcerative colitis undergoing polypectomy. Inflamm Bowel Dis 2012;18:226-35.

61. Rubio CA, Befrits R, Jaramillo E, et al. Villous and serrated adenomatous growth bordering carcinomas in inflammatory bowel disease. Anticancer Res 2000; 20:4761-4.

62. O'Brien MJ, Yang S, Mack C, et al. Comparison of microsatellite instability, $\mathrm{CpG}$ island methylation phenotype, BRAF and KRAS status in serrated polyps and traditional adenomas indicates separate pathways to distinct colorectal carcinoma end-points. Am J Surg Pathol 2006;30:1491-501. 
63. Chaubert P, Benhattar J, Saraga E, et al. K-ras mutations and $\mathrm{p} 53$ alterations in neoplastic and non-neoplastic lesions associated with longstanding ulcerative colitis. Am J Pathol 1994;144:767-75.

64. Bossard C, Denis MG, Bezieau S, et al. Involvement of the serrated neoplasia pathway in inflammatory bowel disease-related colorectal oncogenesis. Oncol Rep 2007;18:1093-7.

65. Soetikno RM, Gotoda T, Nakanishi Y, et al. Endoscopic mucosal resection. Gastrointest Endosc 2003;57:567-79.

66. Saito Y, Uraoka T, Yamaguchi Y, et al. A prospective, multicenter study of 1111 colorectal endoscopic submucosal dissections (with video). Gastrointest Endosc 2010;72:1217-25.

67. Uraoka T, Parra-Blanco A, Yahagi N. Colorectal endoscopic submucosal dissection in Japan and Western countries. Dig Endosc 2012;24:80-3.

68. Uraoka T, Parra-Blanco A, Yahagi N. Colorectal endoscopic submucosal dissection: Is it suitable in western countries? J Gastroenterol Hepatol 2013;28:406-14.

69. Draganov PV, Gotoda T, Chavalitdhamrong D, et al. Techniques of endoscopic submucosal dissection: Application for the Western endoscopist? Gastrointest Endosc 2013;78:677-88.

70. Repici A, Hassan C, De Paula Pessoa D, et al. Efficacy and safety of endoscopic submucosal dissection for colorectal neoplasia: A systematic review. Endoscopy 2012;44:137-50.

71. Iacucci M, Eustace G, Uraoka T, et al. Endoscopic submucosal dissection in the colorectum: Feasibility in the Canadian setting. Can J Gastroenterol 2013;27:689-93.
72.. Kuroki Y, Hoteya S, Mitani T, et al. Endoscopic submucosal dissection for residual/locally recurrent lesions after endoscopic therapy for colorectal tumors. J Gastroenterol Hepatol 2010;25:1747-53.

73. Wanders LK, Dekker E, Pullens B, et al. Cancer risk after resection of polypoid dysplasia in patients with longstanding ulcerative colitis: A meta-analysis. Clin Gastroenterol Hepatol 2013: S1542-3565.

74. Jonathan A, Leighton BS, Baron TH, et al. ASGE guideline: Endoscopy in the diagnosis and treatment of inflammatory bowel disease. Gastrointest Endosc 2006;63:558-65.

75. Eaden JA, Abrams KR, Mayberry JF. The risk of colorectal cancer in ulcerative colitis: A meta-analysis. Gut 2001;48:526-35.

76. Wong NA, Mayer NJ, MacKell S, et al. Immunohistochemical assessment of $\mathrm{Ki} 67$ and $\mathrm{p} 53$ expression assists the diagnosis and grading of ulcerative colitis-related dysplasia. Histopathology 2000;37:108-14.

77. Sato A, MacHinami R. p53 immunohistochemistry of ulcerative colitis-associated with dysplasia and carcinoma. Pathol Int 1999;49:858-68.

78. Smith LA, Baraza W, Tiffin N, et al. Endoscopic resection of adenoma-like mass in chronic ulcerative colitis using a combined endoscopic mucosal resection and cap assisted submucosal dissection technique. Inflamm Bowel Dis 2008;14:1380-6.

79. Velayos FS, Loftus EV, Jess T, et al. Predictive and protective factors associated with colorectal cancer in ulcerative colitis: A case-control study. Gastroenterology 2006;130:1941-9. 


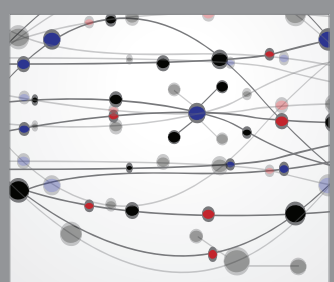

The Scientific World Journal
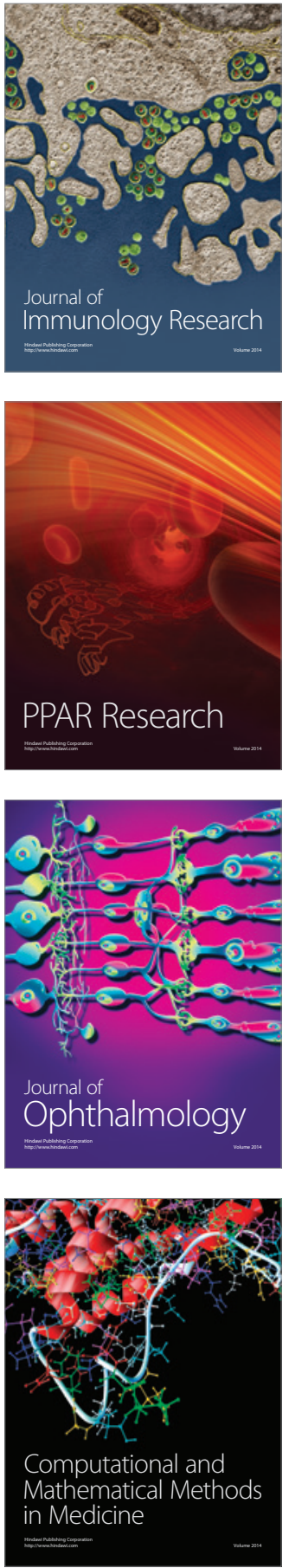

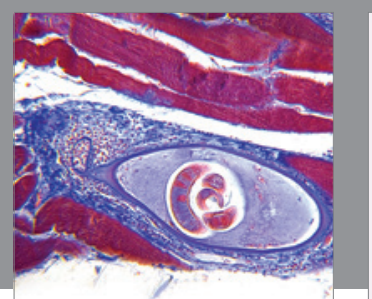

Gastroenterology Research and Practice

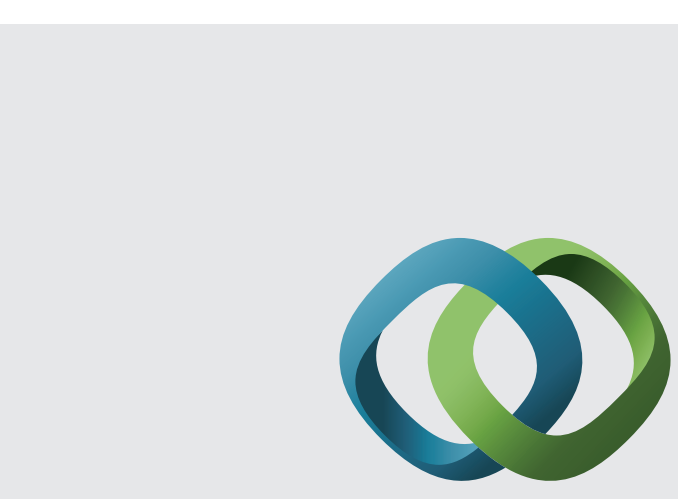

\section{Hindawi}

Submit your manuscripts at

http://www.hindawi.com
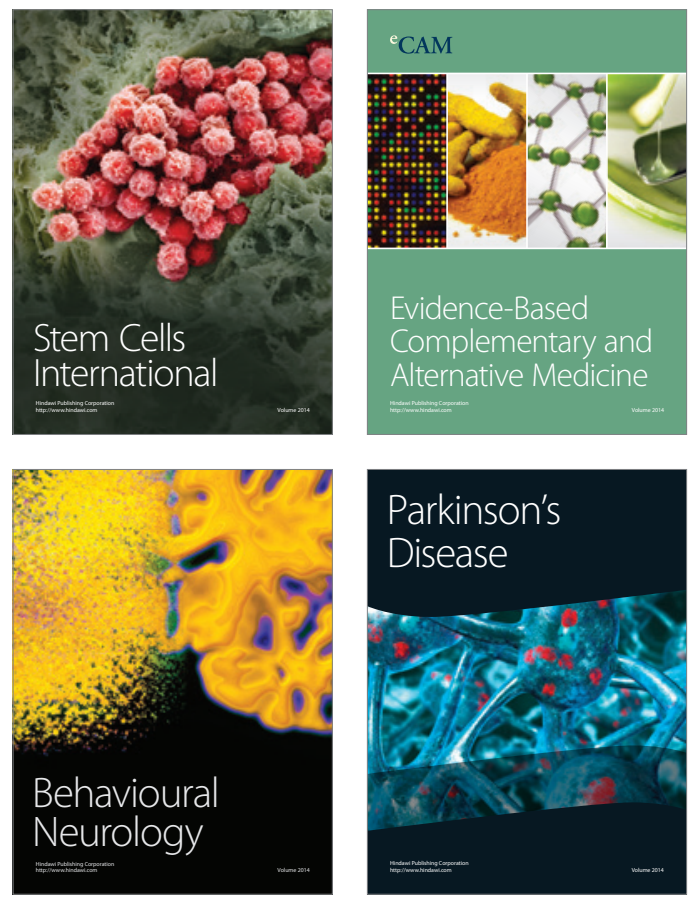
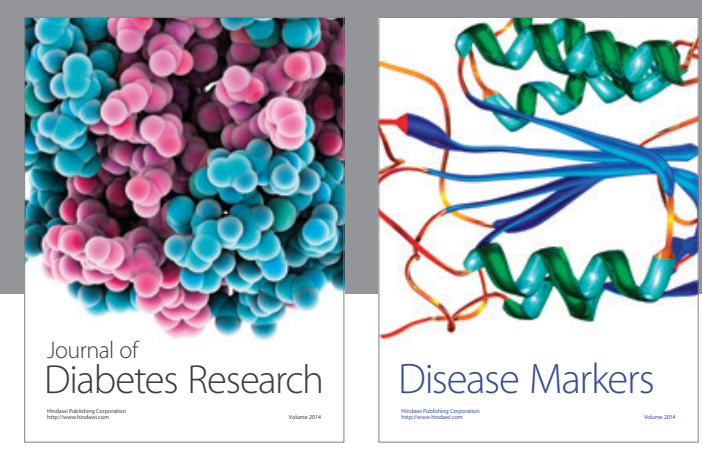

Disease Markers
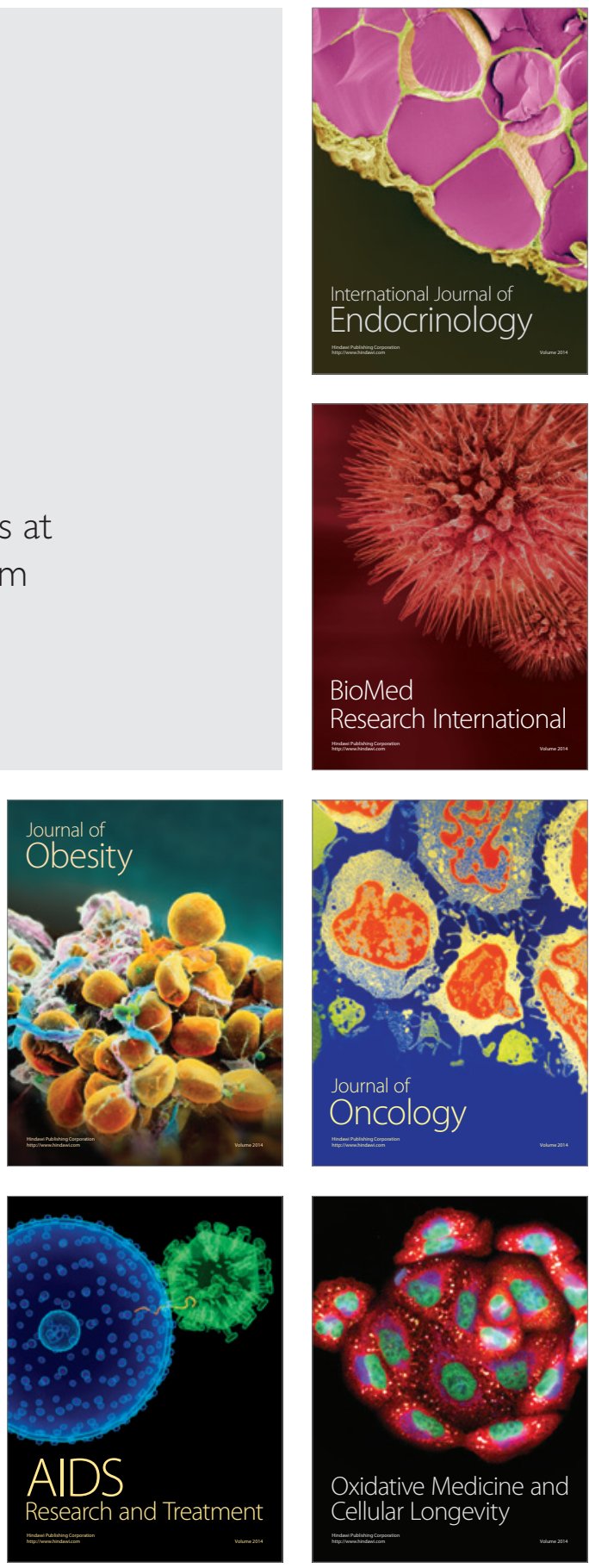